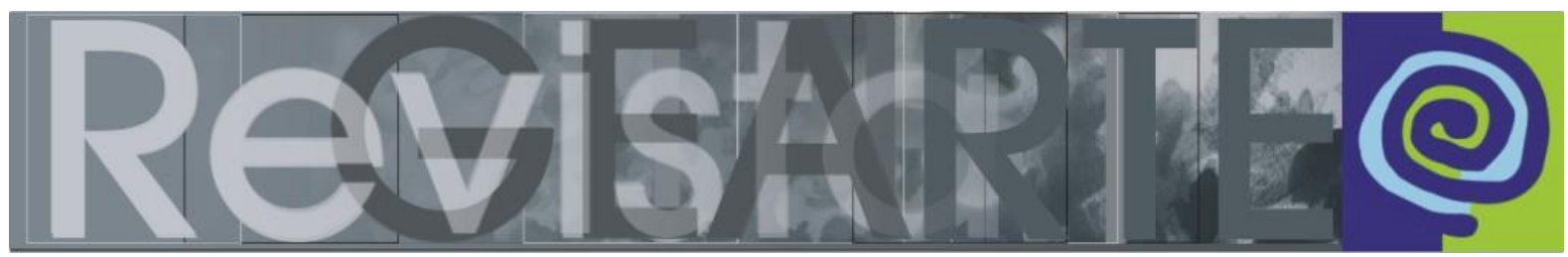

ISSN 2357-9854

\title{
Fotografia "dentrofora" da escola: representação, apresentação e tradução do mundo juvenil. Retratos parciais.
}

\author{
Vanessa de Andrade Lira dos Santos (Universidade Estadual do Rio de Janeiro - \\ UERJ, Duque de Caxias/RJ, Brasil)
}

\begin{abstract}
RESUMO - Fotografia "dentrofora" da escola: representação, apresentação e tradução do mundo juvenil. Retratos parciais. - Explorar as imagens através do ato fotográfico não se trata apenas de observar e enquadrar o real em estruturas bidimensionais, mas se configura como síntese entre o que se está a observar e a intencionalidade do observador. Na conjuntura atual, considerando o registro fotográfico como experiência impregnada na sociedade, tem-se uma sensação de saturação de suas formas de apresentar e representar o mundo, encarando a repetição do ato como esvaziadora de seus sentidos para os sujeitos que produzem e que se veem registrados cotidianamente. Ligando o ato de fotografar às vivências juvenis, "dentrofora" da escola, é possível vislumbrar a presença e a potência desses registros nas várias formas de exposição que a ferramenta e seus usos sugerem. $\mathrm{O}$ objetivo desta empreitada será desvelar, através do ato, fotográfico maneiras estéticas de dizer e de criar da juventude.
\end{abstract}

PALAVRAS-CHAVE

Fotografia. Juventude e escola. Colagem.

ABSTRACT - Photography inside/out the school: representation, presentation and translation of the youth world. Parcial pictures - Exploring the images through the photographic act is not only about observing and framing the real in bi-dimensional structures, but it is set as a synthesis of what is observed and the intentions of the observer. In the current conjuncture, considering the photographic register as an impregnated experience in society, if there is a sensation of saturation of the ways of presenting and representing the world, facing the repetition of the act as empting its senses to the subjects that produce and have been registered daily. Connecting the act of photographing and the juvenile life experiences inside and outside the school, it is possible to glimpse the presence and the potency of this records, in the many ways of exposition that the tool and its uses suggest. The objective of this contract will be unveiling through the photographic act aesthetic ways of telling and creating youth.

KEYWORDS

Photography. Youth and school. Collage.

Diversas são as formas de pensar as imagens fotográficas dentro e fora no espaço escolar, já que elas impregnam o cotidiano de todos nós. É possível utilizá-las como recursos documentais e também como registros estéticos produzidos pelos indivíduos e pelo coletivo. A temática que se desenrola tem como objetivo pensar de maneira reflexiva o conceito fotografia e, posteriormente, desdobrar suas possibilidades através de três produções imagéticas, recorte de uma experiência criativa realizada por jovens alunos do nono ano, nas aulas de artes visuais, de uma 
escola da rede pública do Rio de Janeiro. A expressão "dentrofora" fornece uma pista acerca da impossibilidade de se pensar a fotografia, o espaço escolar e as juventudes como instâncias descoladas das dinâmicas e dos espaços que representam. Diante disso, se faz necessário primeiramente compreender os sentidos do ato fotográfico e as formas de interpretar esta experiência técnica e estética.

Como nos apresenta Flusser (1985, p. 7), “o tempo projetado pelo olhar sobre a imagem é o eterno retorno", isto é, a linearidade do tempo é rompida no ato fotográfico nos permitindo olhar para o índice, resultando nesta experiência através de infinitas perspectivas. Assim, causas e efeitos são reelaborados em uma circularidade que reinventa o olhar, trazendo à tona detalhes que poderiam seguir imunes à observação e ao julgamento de quem observa e participa do real. É o que Flusser (1985, p. 7) chama de "contexto mágico das relações reversíveis" que dota a imagem de seus múltiplos sentidos, e é na circularidade que rompe com a linearidade temporal, que de fato significamos a reversibilidade das imagens diante da vida que passa.

No tempo linear, o nascer do sol é a causa do canto do galo; no circular, o canto do galo dá significado ao nascer do sol, e este dá significado ao canto do galo. Em outros termos: no tempo da magia, um elemento explica o outro, e este explica o primeiro". (FLUSSER, 1985, p. 7)

As imagens tradicionais, trazendo aqui nossa perspectiva para o universo do desenho e da pintura, demandam não só um posicionamento imaginativo, mas principalmente produtivo diante do mundo. O sentido de "produtivo", entretanto, não se liga diretamente ao conceito de produtividade relacionado ao aparato capitalista, mas ao ato que depende não só de esforço mental, mas também físico. Assim, o fazer artesanal, que exige passos progressivos diante do material e do imaginal utilizados, se desdobra em um ritmo temporal que inclui o processo como força agregadora de significados sensíveis ao que é produzido. As imagens técnicas, trazendo nossa reflexão para o campo da fotografia, a cada desenvolvimento tecnológico que a contemporaneidade traz consigo, se distanciam do processo do fazer, trazendo novos significados ao próprio encadeamento temporal que vigorou ao longo da história. Nas reflexões que elaboramos, com base nos registros fotográficos e nas intervenções visuais dos jovens a partir deste aparato técnico, não cabe compreender o processo 
apenas como produção de uma superfície estetizada, mas empreender energia para ver, mesmo que parcialmente, os sentidos que o próprio ato de fotografar desvela, e quais os novos sentidos reconfigurados na observação, manipulação e reflexão dessas imagens captadas. É no processo que se inicia a partir do "gesto caçador" (FLUSSER, 1985), e que se desenrola através da observação e da narração dos registros produzidos e, mais adiante, que se reconfigura em reinvenções, que nossas proposições práticas trazem a juventude e suas imagens para o campo da pesquisa.

A maneira de desenrolar as experiências fotográficas não segue padrões técnicos de observação, não estamos aqui na posição de estudiosos de categorias fotográficas e não pretendemos utilizá-las como material refinado com o papel de ilustrar o trabalho. Neste sentido, ouvimos a mesma voz que inquietou Barthes (1984, p.17): "(...)uma voz importuna (a voz da ciência) então me dizia em tom severo: Volte à fotografia. O que você vê aí e que o faz sofrer inclui-se na categoria 'Fotografia de amadores'(...)". Se considerarmos como amadorismo os registros produzidos cotidianamente, motivados por necessidades que não se enquadram em métodos e não almejam objetivos formais, então encontraremos nessa natureza amadora vestígios dos modos de ser dos jovens e dos lugares que habitam.

Considerando o ritmo que a contemporaneidade imprime à vida, o ato fotográfico se intensifica como recorte do real e como recondução desta atmosfera imagética para uma nova realidade que se manifesta como "tempo capturado". Cabe ressaltar que esta captura é imaginária, já que a vida é prioritariamente movimento. Dubois (1993) nos apresenta o ato fotográfico como uma produção que desloca "o instante à perpetuação", não no sentido de reconfigurá-lo, mas de, a partir dele, produzir um registro que imobiliza um instante como uma experiência memorável. $\mathrm{E}$ esta experiência memorável confirma a natureza fundamental da fotografia: ato que sempre remete a algo. Por isso Barthes (1984, p. 16) afirma: "Seja o que for o que ela dê a ver e qualquer que seja a maneira, uma foto é sempre invisível: não é ela que vemos." O que ele nos deseja esclarecer é que a máquina, que magicamente registra um instante, é um instrumento que serve ao real. $E$ este ato de servir a torna indiscutivelmente um meio, a superfície de material que sustenta a imagem não existe para além da imagem que sustenta. Esta questão nos faz voltar ao fator "artesanal" 
de que refletimos anteriormente, já que a tecnologia atual passa a descartar a dinâmica da feitura manual de uma imagem.

Quando um pintor produz sua obra, ele carrega em sua atitude elementos e instrumentos fundamentais para o desenvolvimento de sua tarefa: o tempo que transcorre em movimento na medida em que produz; seus instrumentos técnicos que Ihes servem para colocar em contato tinta e tela; sua habilidade visual e motora, para traduzir ou reconfigurar as imagens que observa e torna experiência prática.

O ato de pintar e o que ocorre no processo de produção ainda carrega o que de movimento existe neste transcorrer, diferente do ato fotográfico que acontece como um disparo instantâneo sobre o real. Esta mudança de perspectiva já demanda uma nova maneira de olhar e de pensar o real. O contato físico entre olhar, mão tinta e tela é substituído por um contato "olhar/máquina". Não significa que se desconsidere o aspecto natural e biológico do olhar, mas se percebe reconfigurações nesse olhar na medida em que pode se desdobrar através de um instrumento tecnológico que, em alguns momentos, chega a se confundir com ele. Por fim, a materialidade que se observa em uma pintura ainda é matéria - salvo os casos de pinturas renascentistas, por exemplo, que tendem a "esconder" sua materialidade sobre as imagens produzidas. De maneira geral, mesmo representando um objeto real, tinta ainda é tinta, tela ainda é tela e o gesto humano ainda permite visualizar as diferenças entre as diversas imagens produzidas artesanalmente pelo mesmo artista.

A partir da constatação de que a fotografia está condicionada, mesmo que parcialmente, ao que o observador vê, seguimos em direção ao que é observado. $O$ que se dá de singular na experiência fotográfica é a junção desta tríade: máquina, observador e observado. Tudo que se desdobra a partir desta relação carrega em si traços de um jogo de escolhas, mais ou menos aparente, a partir destas dimensões postas em jogo. Barthes (1984, p. 23) nos apresenta sua indagação: "No entanto, como o que eu gostaria que fosse captado é uma textura moral fina, e não uma mímica, e como a fotografia é pouco sutil, salvo nos grandes retratistas, não sei como, do interior, agir sobre minha pele." 
Esta textura de que Barthes trata, sendo conduzida para o campo da pintura, significa camadas que, postas umas sobre as outras, promovem à imagem um aspecto de aproximação com o real. Não como uma representação do real, mas com a materialidade do real. Trazendo para o campo da subjetividade, esta textura se insinua como as diferentes camadas que dispostas, umas sobre as outras, produzem o que chamaremos de 'identidades abertas'. Em cada momento- e a experiência fotográfica se configura como um momento privilegiado - essas camadas são dispostas de acordo com o grau de envolvimento e intimidade que cabe nas diversas relações produzidas através destes contatos. No entanto, não é possível conceber na imagem a totalidade do que se desdobra no real e, por sua parcialidade, ela carrega vestígios que, ao serem observados, podem reduzir este real ou ampliar suas potencialidades imaginativas, mas nunca apresentá-lo em sua natureza inicial.

(...) sou "eu" que não coincido jamais com minha imagem; pois é a imagem que é pesada, imóvel, obstinada (por isso a sociedade se apoia nela) e sou "eu" que sou leve, dividido, disperso e que, como um ludião, não fico no lugar, agitando-me em meu frasco (...). (BARTHES, 1984, p. 24)

Podemos considerar este "advento de mim mesmo como outro" (Barthes, 1984, p. 25) como um elemento sedutor da experiência fotográfica para a juventude. Esta possibilidade de ser outro, que permeia o imaginário dos sujeitos ao longo da história, vê na fotografia um mecanismo não somente de apresentação, mas sobretudo de representação do mundo. Este representar, de alguma forma, "imobiliza gestos" e soa como uma resolução ordenada do que cabe na imagem. É como se a fotografia desse sentido à tentativa de captar esse "o que se agita em meu frasco", pois a sensação de inconsistência do tempo que corre embaralha e desloca a juventude e seus lugares de "aparição". Assim, o ato fotográfico se dá como a expressão de um estar no mundo, mesmo que não conclua em si todas as facetas de quem o experimenta, embalado pela memória e pelos rastros do que já foi presença. A própria noção de memória é reconduzida na atualidade quando os intervalos dos registros diminuem drasticamente. O tempo de 'maturação' dos acontecimentos e de sua conversão em memória comprime-se de tal forma que os processos de tradução nem sempre chegam a promover o que chamaríamos de memorável. O ato não "esfria" e já vira passado, sendo rapidamente sobreposto por outros atos, que por sua vez podem rapidamente alcançar o legado do esquecimento. Neste sentido, pensar a fotografia e 
reconduzir o olhar para essas imagens que passam, pode significar para as juventudes repetir os olhares sobre si mesmos e sobre os outros.

(...) o instigante modo de ver a si mesmo como alguém que passa, que some no tempo, numa velocidade incontrolável, o que tem levado muitos de nossos jovens a agarrar-se, comoventemente, a seu passado tão próximo, como se ele pudesse escapar e abandoná-los irremediavelmente. (SCHWERTNER; FISCHER, 2012, p. 415)

Se a imagem fotográfica, para muitos destes jovens, de fato os representae apresenta ao mundo, então a sobreposição destes registros funciona como a 'sobreposição de esquecimentos', como se o apagamento do registro como intervenção sobre si e sobre os outros trouxesse o apagamento de sua própria presença. E se o que vira aparência é o "frasco", permitir uma reconfiguração deste tempo que passa através de novos e repetidos olhares sobre as imagens, que já foram sobrepostas por outras imagens, pode ser uma chave para resgatar ao menos os vestígios do "que se agita em meu frasco" (BARTHES, 1984, p. 24). É "o que se agita" que se possibilita revisitar, já que a produção de saberes sobre si e sobre o outro se intensifica a partir de revisitações. O desafio posto é revisitar. Revisitar as imagens produzidas pelos jovens, pois resgatar a experiência do tempo pode significar resgatar sentidos que permanecem empilhados nas camadas sobrepostas de "memórias não maturadas". Ao mesmo tempo em que a imagem se prende à realidade que foi sua fonte, ela insinua diferentes narrativas de acordo com quem a processa, e indicia novas leituras a quem interpreta essas projeções. Como acrescenta Manguel (2001, p. 28), "nenhuma narrativa suscitada por uma imagem é definitiva ou exclusiva, e as medidas para aferir a sua justeza variam segundo as mesmas circunstâncias que dão origem à própria narrativa."

Assim, chegamos à conclusão de que é improvável narrar ou enxergar de forma única e precisa as imagens dispostas das produções juvenis, já que elas estão definitivamente descoladas da realidade que as inspiraram e da fisicalidade que as produziram. Essas imagens funcionam agora como indícios de acontecimentos e como fontes para novas narrativas, devemos, portanto, encarar sua natureza descolada das circunstâncias que a geraram como nova possibilidade de produzir narrativas. Antes das imagens, que são visualidades que as ações nos deixam como seus resquícios, "o ato criador é ato de aprender a iniciar um gesto no mundo" 
(RICHTER, 2006, p. 243). E se a partir deste gesto se aprende, "é preciso 'desaprender' como estratégia de devolver à razão sua função turbulenta e agressiva” (RICHTER, 2006, p. 246).

Falar a respeito de imagens parece mais confortável quando partimos de um escopo teórico, que utilizamos como uma rede de apoio a qual baliza tudo aquilo que nos arriscamos a analisar. Falamos de suas relações com aspectos teóricos, de seus conteúdos históricos e das conexões que produzem quando chocadas umas com as outras. É possível até adentrar no complexo campo da semiótica, e obter opções plausíveis e condizentes com teorias tradicionais e empreendimentos reflexivos contemporâneos. Podemos divagar - sempre respaldados pelos seguros conteúdos teóricos e legitimados- sobre os contextos das imagens e cruzá-las com palavras, na tentativa de justificar sua presença em uma pesquisa acadêmica. Podemos construir e reconstruir muitas reflexões a partir do conceito imagem.

Assim, o desafio desta etapa da pesquisa vem com a seguinte questão: Como interpretar as imagens produzidas pelos jovens, quando estas nos arrebatam antes dos textos que poderiam "justificá-las"? O que buscamos deixar claro nas "análises" que seguem é o caráter de experimento, que se desdobra como necessidade de abertura à diversidade de leituras que suscitam. São muitas as maneiras de encarar essas imagens produzidas em diferentes momentos, e guiadas por incontáveis motivações. Mesmo considerando o espaço escolar como ambiente privilegiado para o andamento e a conclusão dos trabalhos plásticos realizados pelos jovens, não é possível "neutralizá-los" a partir de uma leitura definitiva, já que tratamos de experiências reais e, consequentemente, múltiplas.

Cabe ressaltar que as imagens, muitas vezes, podem ser consideradas como elemento ilustrativo, dependendo das implicações que os diversos documentos que as detém carregam como caráter intencional. No entanto, o objetivo desta "análise" é considerar a imagem como parte, não ilustrativa ou motivadora do trabalho, mas como ferramenta do discurso. Elas não estarão presentes nessa reflexão no sentido de justificar desdobramentos teóricos, ou para servir de alavanca metodológica para dinâmicas discursivas previamente estabelecidas. O que pretendemos produzir é uma conversa imagem/texto, que não se dá em uma esfera hierarquizante, mas que evolui 
como um jogo de complementaridade. Não se pretende concluir uma interdependência, já que ambas as esferas, textual e imagética, são vivas e ativas independentemente de sua articulação. O que se entende como relevante, particularmente nesta reflexão que se desdobra, está amparado na seguinte postura: as pesquisas visuais juvenis, abordadas neste trabalho acadêmico, se intensificam ao cruzarmos as "falas dos textos" as "falas das imagens".

Mesmo sendo o desejo de todo pesquisador, não apenas acariciar, mas abraçar e reter todos os fluxos que transbordam de uma experiência cotidiana, temos a consciência da impossibilidade deste feito. Não por incompetência do pesquisador, nem por inconstância dos sujeitos envolvidos no processo (em que o próprio pesquisador participante também se enquadra), mas pelo fato inabalável de não se poder aprisionar o que vive e o que é vida. Pesquisa alguma será capaz de por a vista todos os meandros do real, visto que o próprio ato de pesquisar é uma intensa tradução, e toda tradução implica passar de um "estado inicial" para "outra língua". Tanto o texto, quanto a imagem, são "outras línguas" em relação ao real, e não é sequer possível produzir qualquer coisa quando não se tem consciência desta dimensão, de certa forma, ficcional do produzido. Ainda assim, os indícios do vivido podem nos proporcionar intensas experiências do real, já que o ato de produzir é uma nova realidade diante do "índice" que o incitou, e a maneira, ou maneiras, como dialogamos com estas e tantas outras produções, permitem continuar o ciclo de invenções de outras realidades.

As formas de percepção não são gratuitas nem os relacionamentos se estabelecem ao acaso. Ainda que talvez a lógica de seu desdobramento nos escape, sentimos perfeitamente que há um nexo. Sentimos, também, que de certo modo somos nós o ponto focal de referência, pois ao relacionarmos os fenômenos nós os ligamos entre si e os vinculamos a nós mesmos. (OSTROWER, 2001, p. 9)

Se o que é externo a nós é o que de fato nos afeta, o deslocar, seja de que natureza for, carrega outros deslocamentos que se desdobram. A maneira, ou as maneiras, de se perceber os acontecimentos e os processos de criação, se dão em um cruzamento entre resquícios internos de experiências externas anteriores, e as novas experiências que se dão, deslocando proposições iniciais. Assim, os "pontos focais" das formas de perceber os processos e acontecimentos se deslocam, considerando os interlocutores envolvidos na dinâmica. Falar de processos e falar de 
imagens carrega a relativa parcialidade de quem vive os acontecimentos e de quem dá vida às narrativas que tratam da visualidade. Podemos falar de acontecimentos ocorridos no outro lado do mundo ou no nosso próprio quintal, podemos "aferir dados" que presumimos estáticos ou classificar "objetos de pesquisa" como legítimos para serem validados. Podemos concluir muitas coisas, mas, "ao relacionarmos os fenômenos, nós os ligamos entre si e os vinculamos a nós mesmos".

Com base nessas reflexões, enfatizamos, além da impossibilidade de neutralidade das falas diante das imagens a seguir, as narrativas produzidas a partir destas imagens como sendo toques pontuais a respeito dos processos de criação e das vivências juvenis, presentes nos cotidianos vividos e em suas produções. Tendo em vista a necessidade de proteger e respeitar a identidade de nossos alunos, utilizamos nomes fictícios para "narrar" suas produções. A proposta de atividade prática surgiu partindo das "selfies" produzidas e divulgadas, através das redes sociais, diariamente por nossos alunos. Não se trata de uma pesquisa voltada para as redes sociais e suas possibilidades de exposição de imagens, não neste momento. Os registros fotográficos selecionados e impressos pelos alunos, em sua maioria, chegaram como material de produção antes mesmo de serem expostos em suas redes.

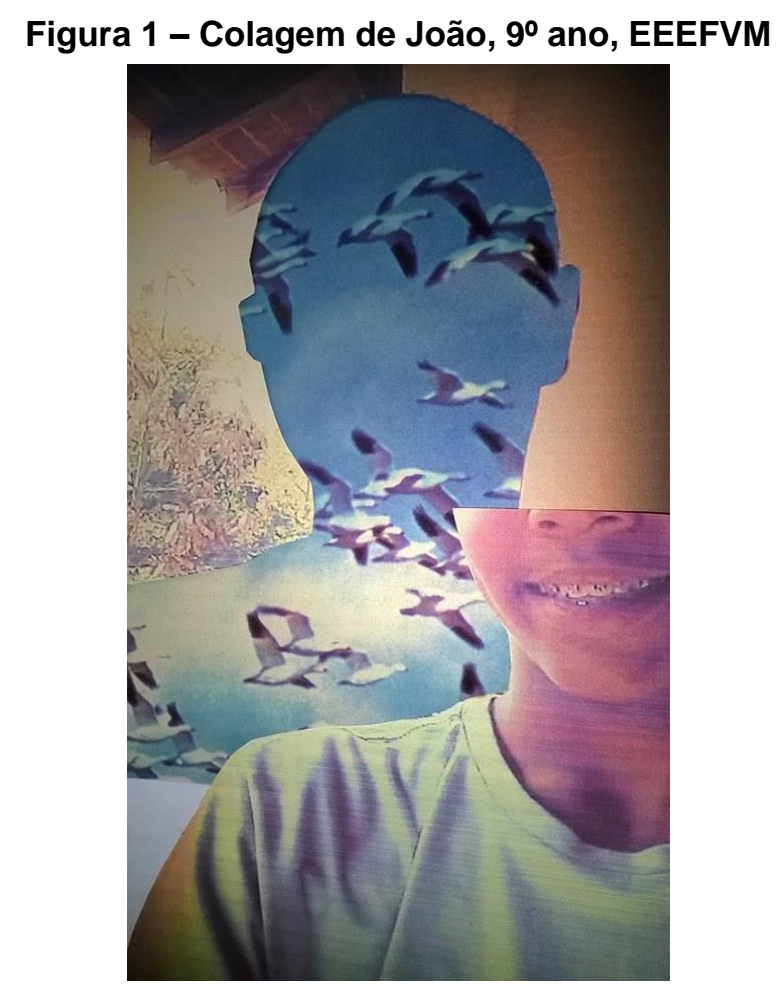

Fonte: arquivo da autora. 
O trabalho foi produzido utilizando um registro fotográfico e o fragmento de uma paisagem, retirado de uma revista. O momento de pesquisa em revistas, por si só, já implica envolvimento com as imagens observadas e, posteriormente, uma tentativa de "contextualização" com o registro fotográfico selecionado como base inicial para o trabalho. A fotografia se apresenta em primeiro plano, com o fragmento do rosto do aluno e o que seria um plano posterior, contendo a "paisagem" da fotografia (se estivéssemos considerando uma representação tradicional, em perspectiva). No entanto, a própria proposta da colagem já sugere uma ruptura com as tradicionais formas de produzir imagens. Figura e fundo e dentro e fora se confundem nos trazendo questionamentos não apenas formais, mas sobretudo subjetivos e metafóricos. O que é paisagem e o que é sujeito? O dentro impregnado pelo fora nos remete a "palavra inventada" utilizada no título e no desenrolar desta pesquisa: "dentrofora". A criação de João nos confunde e nos confirma o que parecia claro e, ao mesmo tempo, tão complexo: tanto na escola como nas próprias experiências imagéticas juvenis, o dentro e o fora ora se confundem, ora se complementam, ora se confirmam como uma mesma dinâmica.

O registro fotográfico, mesmo que selecionado pensando na escola, veio de fora dela. O recorte selecionado para compor a imagem foi escolhido - e não vamos discutir aqui a intensão ou o acaso da escolha - é referência de fora, não simplesmente como paisagem que representa, mas, sobretudo, por fazer parte de uma veiculação que sequer pensou no ambiente escolar ao ser produzida. E estes dois fragmentos materiais dotados de sentidos díspares (salvo por seu suporte material semelhante), com seus contextos bem definidos em suas naturezas iniciais, se cruzam e imprimem na superfície criada novas significações. Mesmo que a proposta inicial não tenha sido uma colagem surrealista, a relação desta experiência estética com a proposta plástica desenvolvida dialoga na afronta das conexões racionais que os fragmentos, em seus contextos originais, apresentavam. João passou a ser parte, fragmento de sujeito, mas sua silhueta denuncia seu contorno geral, e seu conteúdo passa a ser preenchido como uma "metáfora de liberdade".

As colagens surrealistas têm seu fundamento no confronto de imagens díspares, que nos colocam frente a situações absurdas, paradoxais, violentas, nos remetendo a uma realidade que não apresenta qualquer nexo com a realidade 
cotidiana, liberando o espírito para um mundo novo, supra-real, caotizado pelos imprevistos choques de imagens. (BRAUNE, 2000, p. 39)

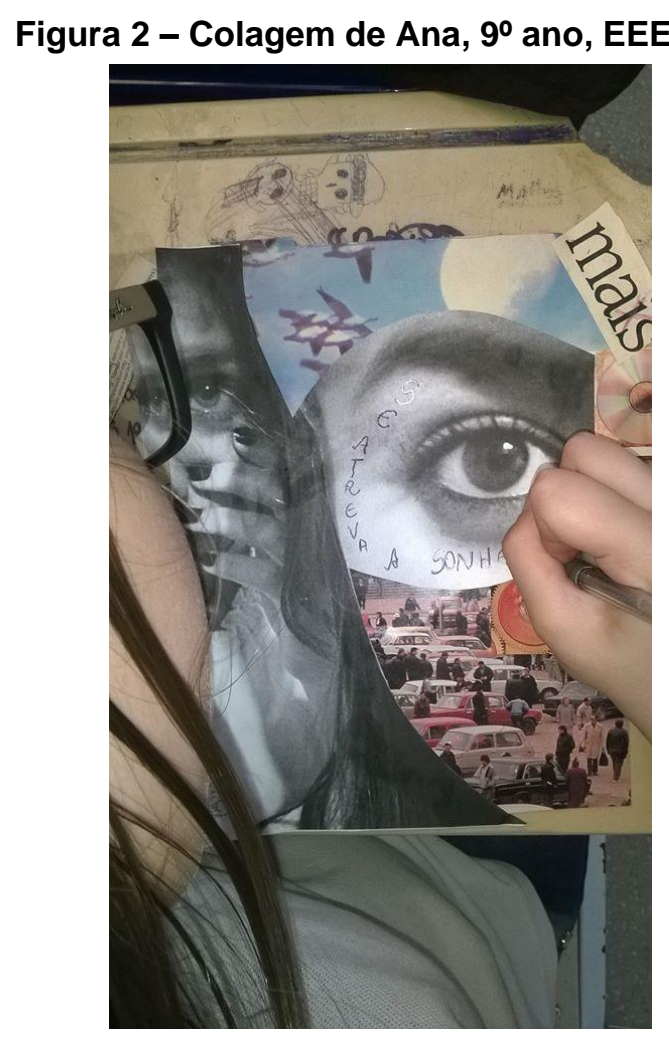

Fonte: arquivo da autora.

A imagem produzida por Ana tem uma parte do céu do João, o olhar de sua "selfie", uma parte do rosto de uma amiga em segundo plano, vários carros e pessoas ocupando desordenadamente uma rua, um pedaço da figura de um C.D. e algumas palavras. $\mathrm{Na}$ imagem geral temos a Ana a produzir. O seu olhar expressivo não a identifica, mas traz consigo a expressividade do seu registro fotográfico. O contraste entre o fragmento de céu, o olhar de Ana e de sua amiga, e o aglomerado de carros e pessoas, falam da mistura, nem sempre precisa, do que nos compõe enquanto sujeitos no mundo. O rosto de Ana agora é composto de vazio e de excesso, assim como os muitos rostos juvenis que se cruzam na escola. Ao fundo, os rabiscos e desenhos da mesa também denunciam restos de passagens de estudantes por essa carteira.

Duas manifestações são postas a partir de palavras: "mais", com seu "i" riscado; e a frase "Se atreva a sonhar", sendo finalizada no exato momento do registro. Palavras, frases e textos preenchem boa parte do tempo escolar, mesmo que nem 
sempre sejam lidas ou ouvidas. Quando, em um trabalho visual, cruzam-se técnica e criação imagética e textual, novos horizontes de abordagens são abertos, já que cada palavra e fragmento de imagem combinados, servem de gatilho para a produção de novos sentidos, impensados antes do encontro.

A palavra "mais", em seu sentido de quantidade, se faz presente na quantidade de estímulos presentes não só no trabalho produzido, mas também na própria dinâmica cotidiana dos jovens. O "mas", que sobra após o "i" ser riscado, traz o "entretanto" como presença na imagem. E é na incompletude da significação do "mas" que, metaforicamente, podemos pensar no transitar juvenil, como etapa de vida "em construção" e, ao mesmo tempo, momento tão consistente e produtivo em si mesmo. Essa incompletude se afirma no "Se atreva a sonhar" de Ana, já que sonhar indicia tanto o devaneio quanto a abertura para novas possibilidades de significar o mundo e sua presença nele. Por que o registro fotográfico para a maioria dos jovens, que se desloca na escola, é tentativa de presença. E a fotografia, transformada pela colagem, desconfigura lógicas e rompe ao mesmo tempo em que reúne.

\footnotetext{
A colagem é, em sentido restrito, uma metáfora: transposta para um mesmo lugar e aí reúne. É fácil ver o que essa atitude apresenta como alternativa em relação à clássica discriminação, separação ou ruptura operante na arte ocidental. A colagem mistura gêneros sem se preocupar com sua economia interior ou sua lógica própria. (MAFFESOLI, 2007, p. 148)
}

O trabalho a seguir descola-se dos registros fotográficos de si mesmos, seguindo em direção às fotos produzidas, considerando o cotidiano e os afetos experienciados pelos jovens em seus espaços pessoais. Não foram exigidas imagens com determinados aspectos simbólicos, a única palavra guia foi "afeto". Tratamos da ideia de afetar e ser afetado por imagens. Na maioria das vezes, o que nos afeta, e também a muitos jovens, está fora do jogo de sentidos e nexos que o ordenamento disciplinar, de dentro e de fora da escola, prescreve. Ao exigir uma justificativa prévia para as imagens selecionadas e compartilhadas pelos jovens, o acontecimento de ler e experienciar estas imagens, como uma proposta no presente, poderia se esvair. 
Figura 3 - Colagem de Maria, 9a ano, EEEFVM

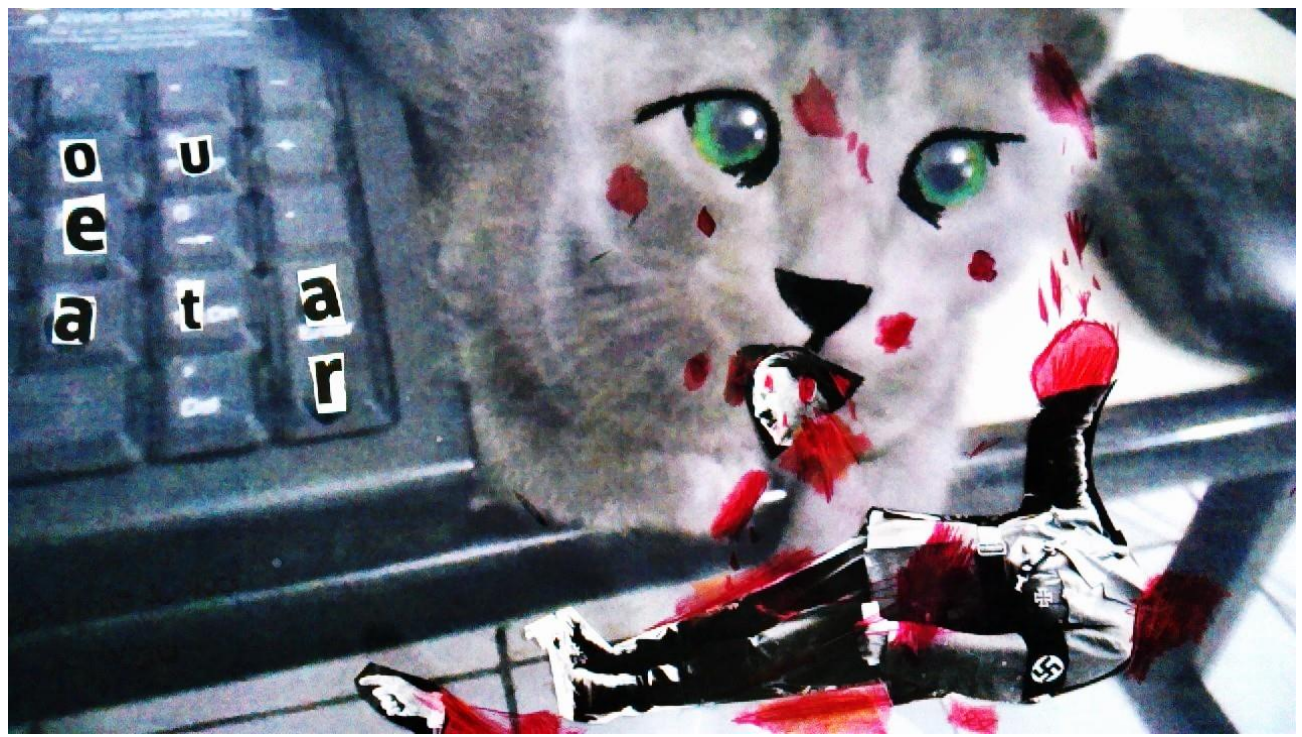

Fonte: arquivo da autora.

Maria, ao apresentar o registro com a imagem de seu gato, antes de qualquer interferência estética posterior a foto, trouxe com ele uma parte de suas vivências diárias, não sendo relevantes aqui justificativas técnicas ou formais para a sua escolha. O que costumamos tratar repetidamente em sala de aula, é que escolhas nem sempre são explicáveis através de lógicas de ordenamento racional. Voltando a fala de Ostrower, "talvez a lógica de seu desdobramento nos escape", mas "sentimos perfeitamente que há um nexo" (2001, p.9). Não se trata aqui de conceber o processo educacional como algo que se guie pelo acaso e pelos tropeços que damos pelo caminho, mas de ter o sentido amplo da educação respeitado na medida em que tomamos as habilidades de criar como fontes inesgotáveis, dentrofora do espaço escolar e em nossas salas de aula. Produzir um discurso, seja ele verbal ou imagético, é profundo processo de criação e de educação, em sua forma mais abrangente e fértil. Talvez a ousadia aqui seja colocar os processos criativos para além do aparato disciplinar da escola, na tentativa de deslocar o conceito educação das simplificações que o atrelam restritamente à informação e a conteúdos acumuláveis e assimiláveis, e reconciliá-lo com sua essência genuína de inventar.

Voltemos à produção estética de Maria. A figura de seu gato chega como uma referência "amena" de sua vivência cotidiana, e muitos elogios são feitos ao olharem para a singela imagem. Ao se apresentar a possibilidade de subverter os sentidos iniciais das imagens, a própria experiência sensível que sem tem ao observá-las tende 
a ser alterada. Ao selecionar o fragmento de revista, que seria unido à imagem inicial através da colagem, Maria abriu campos de discurso que desconfiguram a suposta calmaria do registro inicial, trazendo para o fluxo da observação um recorte com forte carga política. Maria não vivenciou a carga emocional que um representante nazista despertou em seu tempo, só levou consigo a memória temporal de seu gato. Mas reconhece, através de informações do seu tempo, ao menos parte da simbologia presente na postura e nas vestes de um ditador. E este reconhecimento reconfigura os "ânimos" da composição como um todo. O bom e o ruim, o agradável e o repugnante, o manso e a violência, tudo se reinventa na criação resultante, trazendo novas leituras para as perspectivas do observador. A interferência do desenho, mesmo que somente para justificar o preenchimento de cor, traz uma nova dinâmica visual para a produção, já que o vermelho, e seus aspectos simbólicos, considerando a composição estética como um todo, complementam o sentido de sua proposta.

Ao costurar as reflexões teóricas a respeito do ato fotográfico e as produções estéticas que osjovens são capazes de desdobrar a partir de seus registros, é possível vislumbrar a diversidade de maneiras de ver e de reconfigurar imagens na escola. Mais do que isso, é possível considerar que o espaço escolar e as produções criativas que acontecem em seu interior dialogam com a circulação de ideias e experiências cotidianas dos jovens que preenchem seus espaços. Como as colagens produzidas sugerem, é possível cruzar indícios antes díspares. Eis o grande desafio da escola enquanto espaço de criação: possibilitar leituras e processos inventivos dos jovens em seu espaço, considerando toda diversidade imagética e cotidiana existente "dentrofora" dela.

\section{Referências}

BARTHES, Roland. A câmara clara: nota sobre a fotografia. Tradução de Júlio C. Guimarães. Rio de Janeiro: Nova Fronteira, 1984.

BRAUNE, Fernando. O surrealismo e a estética fotográfica. Rio de Janeiro: 7 letras, 2000.

DUBOIS, Philippe. O ato fotográfico e outros ensaios. Tradução Mariana Apponzeller. São Paulo: Editora Papirus, 1993.

FLUSSER, Vilém. Filosofia da caixa preta: ensaios para uma futura filosofia da fotografia. São Paulo: Editora Hucitec, 1985.

MAFFESOLI, Michel. O conhecimento comum: introdução à sociologia compreensiva. Porto Alegre: Sulina, 2007. 
MANGUEL, Alberto. O espectador comum: a imagem como narrativa. In: Lendo Imagens: uma história de amor e ódio. Tradução: Rubens Figueiredo, Rosana Eichemberg e Cláudia Strauch. São Paulo: Companhia das Letras, 2001. p. 15-34.

OSTROWER, Fayga. Criatividade e processos de criação. 19ª edição. Petrópolis: Vozes, 2001.

RICHTER, Sandra. Bachelard e a experiência poética como dimensão educativa da arte. Educação, Santa Maria, v. 31, n. 02, p. 241-254, jul./dez. 2006.

SCHWERTNER, Suzane Feldens; FISCHER, Rosa Maria Bueno. Juventudes, conectividades múltiplas e novas temporalidades. Educação em Revista, Belo Horizonte, v. 28, n.01, p. 395-420, mar. 2012.

\section{Vanessa Andrade Lira dos Santos}

Mestranda em Educação, Cultura e Comunicação em Periferias Urbanas, FEBF-UERJ. Possui pósgraduação em Ensino da Arte pela Universidade Veiga de Almeida (2011) e graduação (licenciatura e bacharelado) em Artes Plásticas pela Universidade do Estado do Rio de Janeiro - UERJ (2005). Atualmente é professora concursada de Artes Plásticas da Fundação de Apoio à Escola Técnica do Estado do Rio de Janeiro - FAETEC e da SEEDUC-RJ. Tem experiência na área de Educação, com ênfase em Ensino da Arte e identidades juvenis.

E-mail: vanessalira25@yahoo.com.br

Currículo: http://lattes.cnpq.br/1061982528145419

Recebido em 12 de junho de 2016 Aceito em 22 de julho de 2016 